\title{
Evaluation of Canine Tipping During its Retraction with Sliding Mechanics.(An in Vitro Study)
}

Nada M. Al-Sayagh BDS, MSc (Asst Prof.)

Afnan J.Ismael BDS, MSc (Asst Prof)
Dept of Pedod, orthod, and Prev Dentistry

College of Dentistry, University of Mosul

Dept of Pedod, orthod, and Prev. Dentistry

College of Dentistry, university of Mosul

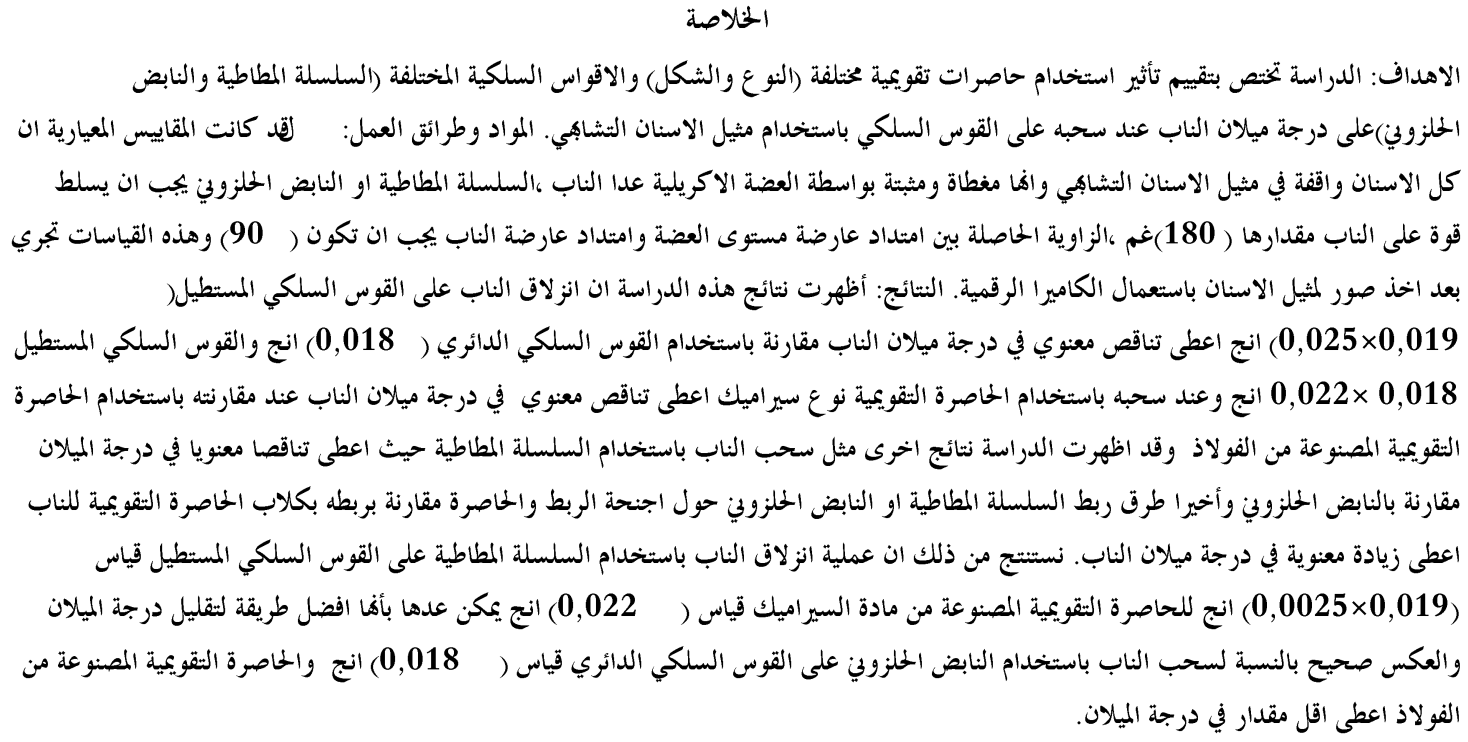

\begin{abstract}
Aims: The present study concerned with the evaluation of the effects of using different bracket,s types (material and design), different arch wire types (shape and size) and different methods of retraction (elastic chain and closed coil spring) on the degree of tipping of canine during its retraction along an arch wire using typodont simulation system (Ormco). Materials and methods: The standardization criteria were all typodont teeth situated in well aligned position, covered and immobilized by the acrylic bite except canine, elastic chain and nickel - titanium closed coil spring exerting $180 \mathrm{gm}$ of force on canine measured carefully by tension gauge., the angle between bite plane extension,s bar and canine,s extension bar was $\left(90^{\circ}\right)$ measured by protractor directly on photographs that were taken for typodont using digital camera from both vertical and horizontal direction. Results: The present study showed that sliding the canine on large rectangular arch wire $(0.019 \times 0.025 \mathrm{inch})$ gave rise to a significant decrease in the degrees of tipping when compared with 0.018 inch and $0.018 \times 0.022$ inch arch wires were used. Also, sliding the canine using ceramic brackets $(0.022)$ inch gave rise to the significant decrease in the degree of tipping than when using stainless steel brackets. Another finding of the present study showed that when using elastic chain as a method of retraction gave rise to a a significant decrease in the degree of tipping as compared with nickel - titanium closed coil spring and lastly the attachment of the method of retraction around the bracket tie wing rather than hook gave rise to the high degree of tipping . Conclusion: It was concluded that the canine retraction with $0.019 \times 0.025$ inch wire on standard ceramic bracket $(0.022)$ inch by elastic chain retraction method could be regarded as the best combination variables that produced less degrees of tipping While the opposite is true for canine retraction with 0.018 inch wire on Roth stain less steel bracket by closed coil spring.
\end{abstract}

Key wards: sliding canine retraction,canine tipping.

Al-Sayagh NM, Ismael AJ. Evaluation of Canine Tipping During its Retraction with Sliding Mechanics.(An in Vitro Study). Al-Rafidain Dent J. 2012; 12(1): 43-51.

Received: $14 / 3 / 2010$

Sent to Referees: $18 / 3 / 2010$

Accepted for Publication: 22/6/2010 


\section{INTRODUCTION}

Canine retraction is an important biomechanical task in orthodontic treatment. It is always desired to distalise a canine bodily without tipping it distally or rotating it distopalatally. The morphology of the canine with its long roots however and greater buccolingual dimensions, can make this task a challenge. ${ }^{(1)}$ Sliding mechanics offers the advantage of controlling canine rotation. ${ }^{(2,3)}$ If canine retraction is carried out with no simultaneous tipping or rotation, the subsequent treatment plan will be facilitated and also the treatment period can be shortened. ${ }^{(4)}$ Since the elastic chain or (coil spring) is placed at the bracket level and not at the center of resistance. The tooth experiences a moment of force in two planes of spaces, one moment rotates the tooth mesial out and the other cause distal tipping of the crown. ${ }^{(5)}$ The major tooth movements that occur during space closure require the rigidity of rectangular stainless steel wire. ${ }^{(6)}$ The tipping of the canine was decreased when the wire size was increased or when the applied force was decreased. ${ }^{(7)}$ The wider the bracket, the easier it will be to generate the moments needed to bring roots together at extraction sites or to control mesiodistal position of roots. ${ }^{(8)}$

The attachments as hook integrated into the bracket, it can be used to shorten the moment arm and thereby decrease the amount of tipping when elastic or springs are used to slide teeth mesiodistaly along an arch wire. ${ }^{(8)}$

The objectives of this study were: To evaluate and compare the degrees of tipping of canine during sliding mechanics using: 1) different arch wire sizes.2) different bracket types.3) different methods of retraction (elastic chain and closed coil spring, and 4) to evaluate the effect of point of force application.

\section{MATERIALS AND METHODS}

The sample of this study consisted of 30 set of orthodontic brackets (only lower incisors, canines and second premolars) divided into different types (standard and Roth for both stainless steel and ceramic 0.022 inch), 300 stainless steel arch wires divided into three sizes $(0.018$ inch, $0.018 \times 0.022$ inch and $0.019 \times 0.025$ inch), 150 closed coil nickel titanium spring and750 elastic chain ring. The study was conducted using two typodont models.

Retraction of canine by sliding mechanics was done by using one possibility of the 30 different combinations (five different brackets and three different arch wires and two methods of retraction) 30 brackets/arch wire/ method of retraction combination were tested 10 times leading to a total of 300 trials. Two typodonts were prepared; one for standard edgewise bracket system and the other for Roth system. The brackets were fixed on metallic teeth using epoxy steel adhesive which is supplied into two tubes (Hardener and resin). Each bracket is positioned in its proper position by the aid of bracket positioning gauge to ensure greater vertical accuracy. ${ }^{(6)}$

This study was conducted using class III typodont wax form, so alignment of the teeth was required to obtain a well aligned teeth, according to other studies, ${ }^{(6,9-11)}$ this was done by placing the arch wires in the lower arch that were progressively upgraded through leveling and aligning, and finally to a $0.019 \times 0.025$ " inch stainless steel wire, after immersing the typodont in a water bath for 5 minutes. The arch wire was ligated to the bracket by using elastomeric ligature because the high variability of tying ligatures makes the use of elastic ligatures the most consisted and reproducible. ${ }^{(12)}$ Both the nickel titanium close coil spring and the elastomeric power chain were stretched to deliver $180 \mathrm{gm}$, using tesion gauge. ${ }^{(13)} 1$. Elastic chain was stretched between the hook on the buccal surface of the molar band and canine bracket where the elastic chain attachment can be circumferential around the four tie wings. ${ }^{(14)}$ or canine hook bracket. ${ }^{(15)}$ As shown in Figure 1 and 2 respectively. 


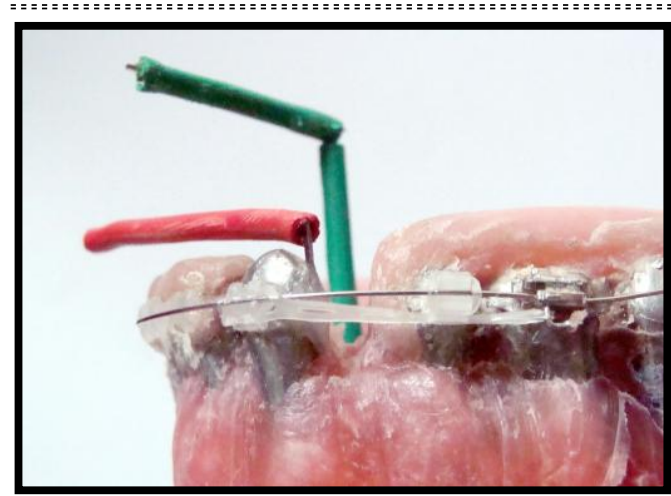

Figure (1) attachment of elastic chain A round the bracket wings.

2. A NiTi closed - coil spring was engaged between the first molar band hook and the hook of canine bracket ${ }^{(2,7)}$ (Fig-

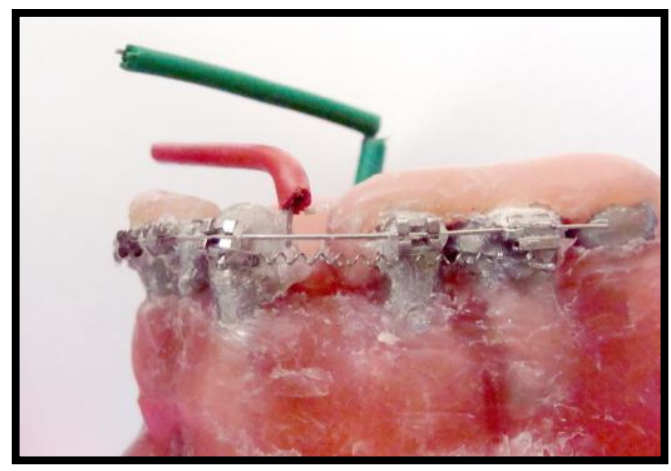

Figure (3): Attachment of closed coil spring on bracket hook

Before starting movement of canine (left canine only) into first premolar site, all typodont teeth were situated in well aligned position and covered by the acrylic bite plane (except canines). The angle between bite plane extension bar and canine extension bar should be $90^{\circ}$ from both vertical and horizontal directions. This angle is considered as canine's bar original angle.

Degree of canine's tipping after movement:

Measurements were made according to Huffmann and Way method. ${ }^{(16)}$ and Ziegler and Ingervall. ${ }^{(14)}$ Method with some modifications. A typodont is photographed using digital camera, ${ }^{(9,17)}$ with transverse projection from right side of typodont, directly toward left canine where the angle between canine extension bar and bite plane extension bar is exposed and then it can be measured directly on the photograph using protractor, this angle is

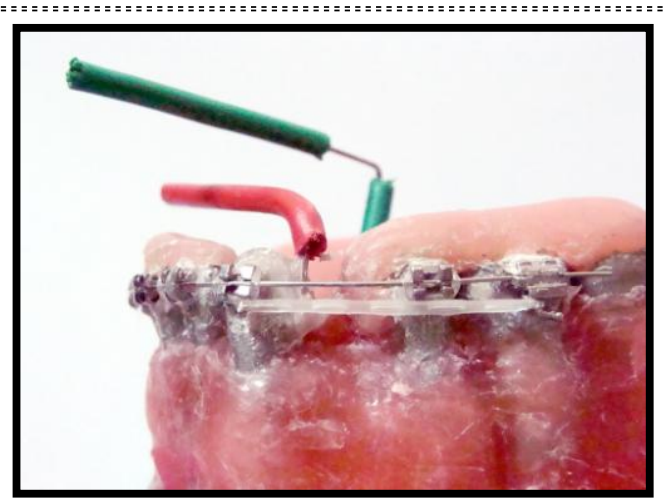

Figure (2) attachment of elastic chain on the bracket hook.

ure3) or attached to the canine bracket by ligature wire over the ligature elastic (Figure 4). ${ }^{(12)}$

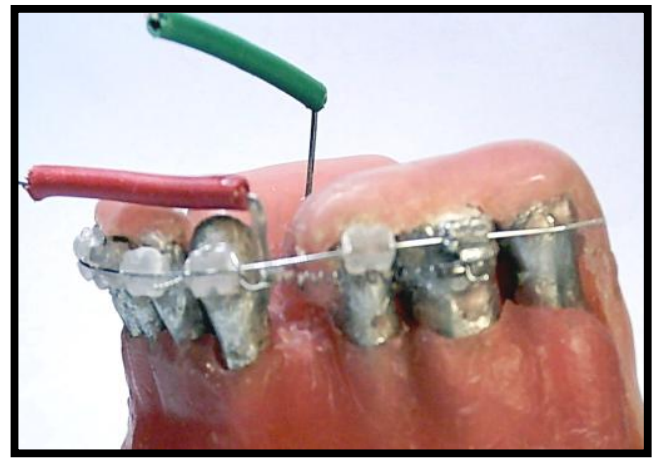

Figure (4): Attachment of closed coil spring around bracket wings

considered as canine's bar inclination angle

Therefore; Degree of canine tipping = canine's bar original angle - canine's bar inclination angle

Before measurements, it's important to establish the followings:

Digital camera is engaged vertically onto the wood table between two pieces of wood that luted above the wood table to maintain stable position of digital camera during photograph exposure.

The metallic base that will receive the typodont is fixed horizontally onto the wood table by screws to maintain stable position of typodont during photograph exposure where the typodont slides in a particular area in the metallic base to end with stable position.

The distance between the digital camera and the typodont is fixed during all measurements $(19.5 \mathrm{~cm})$.

The data were analyzed by using Sta- 
tistical Package for Soft ware System (SPSS version 11.0 Inc., Chicago) Program was used.

1) Descriptive statistics: to show minimum and maximum values, meam and standard deviation for each variable and in each method of measurements. 2) Analysis of Variance (ANOVA): data achieved from previous measurements were initially analyzed by using the three way ANOVA test. 3) Duncan's Multiple Range test: These data were then analyzed by Duncan's Multiple Range test to determine the significant differences among the groups.

\section{RESULTS}

The descriptive statistics that includes mean, standard deviations, minimum and maximum values for the degree of tipping of the 30 experimental groups used are listed in Table (1). The results of Duncan's Multiple Range test in the present study are also listed in Table (1), showed that using nickel - titanium closed coil spring along 0.018 inch wire on the brackets of both stainless steel and ceramic in standard and Roth design gave rise to the highest mean for the degree of tipping, on the other hand using elastic chain that attached to the hook of Roth stainless steel bracket on $0.019 \times 0.025$ inch wire gave rise to the lowest one. The remaining groups distributed on statistical levels between the higher and lower levels of mean.

Comparison of the Degree of Tipping of Canine among Different Bracket Types:

Duncan's Multiple Range test in Table (2) showed significant difference of the degree of tipping of canine at $(P \leq$ 0.05 ) among five types of bracket for three types of arch wire by elastic chain and closed coil spring. In elastic chain retraction group for the three types of arch wire, the stainless steel bracket (standard and Roth) gave rise to the highest mean value of the degree of tipping than that in ceramic bracket. However, there was no significant difference between Roth and standard type for stainless steel and ceramic bracket in three arch wires except in the $0.018 \times 0.022$ inch wire that showed the Roth ceramic bracket had higher degree of tipping than standard ceramic. Also in closed coil spring retraction group, the Roth stainless steel bracket gave rise to the highest mean value of the degree of tipping for all three types of arch wire. However, there was no significant difference between ceramic and stainless steel bracket on 0.018 inch wire.

Comparison of the Degree of Tipping of Canine among Three sizes of Arch Wire:

Duncan's Multiple Range test, Table (3) and Figure (1) showed significant differences for the degree of tipping among three types of arch wires for five types of brackets by elastic chain and closed coil spring.

In both methods of retraction, sliding the canine along 0.018 inch wire by using five types of brackets produced the highest mean value of the degree of tipping, on the other hand, using $0.019 \times 0.025$ inch wire produced the lowest one, while sliding the canine along $0.018 \times 0.022$ inch arch wire fell and distributed on a statistical level between the other two arch wires. However, there was no significant difference between $0.018 \times 0.022$ inch and $0.019 \times 0.025$ inch arch wires in all types of stainless steel bracket and standard ceramic bracket in elastic chain retraction group.

Comparison of the Degree of Tipping of Canine between Elastic Chain and Closed Coil Spring:

Duncan's Multiple Range test in Table (3), also showed significant differences in the degree of tipping at $(P \leq 0.05)$ between elastic chain and closed coil spring in each bracket type.

In all groups closed coil spring showed highest mean value for the degree of tipping of canine than elastic chain except on $0.019 \times 0.025$ inch wire for both stainless steel and ceramic standard brackets that showed no significant differences in the degree of tipping of canine. 
Table (1) Descriptive statistics for the degree of tipping of canine.

\begin{tabular}{|c|c|c|c|c|c|c|c|}
\hline $\begin{array}{l}\text { Type of } \\
\text { bracket }\end{array}$ & arch wire & Method of retraction & Mean & SD & Min. & Max. & $\begin{array}{c}\text { Duncan } \\
\text { group }\end{array}$ \\
\hline \multirow{6}{*}{$\begin{array}{c}\text { Standard } \\
\text { Stainless } \\
\text { steel }\end{array}$} & \multirow{2}{*}{0.018 inch } & Elastic chain & 8.4 & 0.7 & 8 & 10 & $\mathrm{~L}$ \\
\hline & & Closed coil spring & 10 & 0 & 10 & 10 & M \\
\hline & $0.018 \times 0.022$ & Elastic chain & 4.8 & 0.63 & 4 & 6 & $\mathrm{DE}$ \\
\hline & Inch & Closed coil spring & 6.4 & 0.7 & 5 & 7 & $\mathrm{GH}$ \\
\hline & $0.019 \times 0.025$ & Elastic chain & 4.7 & 0.48 & 4 & 5 & $\mathrm{DE}$ \\
\hline & Inch & Closed coil spring & 4.4 & 0.52 & 4 & 5 & $\mathrm{CD}$ \\
\hline \multirow{6}{*}{$\begin{array}{l}\text { Roth stain- } \\
\text { less steel }\end{array}$} & \multirow{2}{*}{0.018 inch } & Elastic chain & 8.3 & 0.67 & 7 & 9 & KL \\
\hline & & Closed coil spring & 10 & 0 & 10 & 10 & $\mathrm{M}$ \\
\hline & $0.018 \times 0.022$ & Elastic chain & 4.9 & 0.88 & 4 & 6 & $\mathrm{DE}$ \\
\hline & Inch & Closed coil spring & 6.6 & 0.52 & 6 & 7 & $\mathrm{H}$ \\
\hline & $0.019 \times 0.025$ & Elastic chain & 4.6 & 0.52 & 4 & 5 & $\mathrm{DE}$ \\
\hline & Inch & Closed coil spring & 5.6 & 0.52 & 5 & 6 & $\mathrm{~F}$ \\
\hline \multirow{6}{*}{$\begin{array}{c}\text { Hook Roth } \\
\text { Stainless } \\
\text { steel* }^{*}\end{array}$} & \multirow{2}{*}{0.018 inch } & Elastic chain & 7.3 & 0.67 & 6 & 8 & I \\
\hline & & Closed coil spring & 8 & 0 & 8 & 8 & JKL \\
\hline & $0.018 \times 0.022$ & Elastic chain & 3.8 & 0.92 & 3 & 5 & $\mathrm{AB}$ \\
\hline & Inch & Closed coil spring & 6 & 0 & 6 & 6 & $\mathrm{FG}$ \\
\hline & $0.019 \times 0.025$ & Elastic chain & 3.3 & 0.82 & 2 & 4 & $\mathrm{~A}$ \\
\hline & Inch & Closed coil spring & 5 & 0 & 5 & 5 & $\mathrm{E}$ \\
\hline \multirow{6}{*}{$\begin{array}{l}\text { Standard } \\
\text { ceramic }\end{array}$} & \multirow{2}{*}{0.018 inch } & Elastic chain & 7.8 & 0.79 & 7 & 9 & IJK \\
\hline & & Closed coil spring & 10 & 0 & 10 & 10 & M \\
\hline & $0.018 \times 0.022$ & Elastic chain & 3.4 & 0.7 & 2 & 4 & $\mathrm{AB}$ \\
\hline & Inch & Closed coil spring & 5.8 & 0.79 & 5 & 7 & $\mathrm{~F}$ \\
\hline & $0.019 \times 0.025$ & Elastic chain & 3.5 & 0.53 & 3 & 4 & $\mathrm{AB}$ \\
\hline & Inch & Closed coil spring & 3.9 & 0.74 & 3 & 5 & $\mathrm{BC}$ \\
\hline \multirow{6}{*}{$\begin{array}{l}\text { Roth Ce- } \\
\text { ramic }\end{array}$} & \multirow{2}{*}{0.018 inch } & Elastic chain & 7.6 & 0.52 & 7 & 8 & $\mathrm{IJ}$ \\
\hline & & Closed coil spring & 10 & 0 & 10 & 10 & M \\
\hline & $0.018 \times 0.022$ & Elastic chain & 4.7 & 0.48 & 4 & 5 & $\mathrm{DE}$ \\
\hline & Inch & Closed coil spring & 4.7 & 0.67 & 4 & 6 & $\mathrm{DE}$ \\
\hline & $0.019 \times 0.025$ & Elastic chain & 3.5 & 0.53 & 3 & 4 & $\mathrm{AB}$ \\
\hline & Inch & Closed coil spring & 4.6 & 0.52 & 4 & 5 & $\mathrm{DE}$ \\
\hline
\end{tabular}

- F-value $=143.90 \quad \bullet$ Measurement in degree $\bullet$ Number for each group $=10$.

* Attachment of elastic chain and closed coil spring on the hook of Roth stainless steel bracket while the other types of brackets the attachment around the tie wings. Means with different letters vertically in each arch wire have significant difference at $p \leq 0.05$ - $\mathrm{f}$-value cannot be calculated (division by zero). Measurements in degree 
Table (2): Comparison of the degree of tipping of canine among different bracket types

\begin{tabular}{|c|c|c|c|c|c|c|c|}
\hline \multirow{2}{*}{$\begin{array}{l}\text { Arch } \\
\text { wire }\end{array}$} & \multirow{2}{*}{ Type of bracket } & \multicolumn{3}{|c|}{ Elastic chain } & \multicolumn{3}{|c|}{ Closed coil spring } \\
\hline & & Mean & SD & Duncan & Mean & SD & Duncan \\
\hline \multirow{6}{*}{$\begin{array}{c}\text { 0.018 } \\
\text { inch }\end{array}$} & Standard stainless steel & 8.4 & 0.70 & B & 10 & 0 & B \\
\hline & Roth stainless steel & 8.3 & 0.67 & B & 10 & 0 & B \\
\hline & Hook Roth stainless steel & 7.3 & 0.67 & A & 8 & 0 & A \\
\hline & Standard ceramic & 7.8 & 0.79 & $\mathrm{AB}$ & 10 & 0 & B \\
\hline & Roth ceramic & 7.6 & 0.52 & A & 10 & 0 & B \\
\hline & F-value & & 4.74 & & & - & \\
\hline \multirow{6}{*}{$\begin{array}{c}0.018 x \\
0.022 \\
\text { inch }\end{array}$} & Standard stainless steel & 4.8 & 0.63 & B & 6.4 & 0.70 & $\mathrm{CD}$ \\
\hline & Roth stainless steel & 4.9 & 0.88 & B & 6.6 & 0.52 & $\mathrm{D}$ \\
\hline & Hook Roth stainless steel & 3.8 & 0.92 & A & 6.0 & 0.00 & $\mathrm{C}$ \\
\hline & Standard ceramic & 3.4 & 0.70 & A & 5.8 & 0.79 & B \\
\hline & Roth ceramic & 4.7 & 0.48 & B & 4.7 & 0.67 & A \\
\hline & F-value & & 8.36 & & & 15.00 & \\
\hline \multirow{6}{*}{$\begin{array}{c}0.019 x \\
0.025 \\
\text { inch }\end{array}$} & Standard stainless steel & 4.7 & 0.48 & B & 4.4 & 0.52 & B \\
\hline & Roth stainless steel & 4.6 & 0.52 & B & 5.6 & 0.52 & $\mathrm{D}$ \\
\hline & Hook Roth stainless steel & 3.3 & 0.82 & A & 5.0 & 0.00 & $\mathrm{C}$ \\
\hline & Standard ceramic & 3.5 & 0.53 & A & 3.9 & 0.74 & A \\
\hline & Roth ceramic & 3.5 & 0.53 & A & 4.6 & 0.52 & B \\
\hline & F-value & & 13.44 & & & 26.08 & \\
\hline
\end{tabular}

Means with different letters vertically in each arch wire have significant difference at $p \leq 0.05$ - f-value cannot be calculated (division by zero). Measurements in degree

Table (3) Comparison of the Degree of Tipping of Canine among Three Types of Arch Wire and between Elastic Chain and Closed coil Spring Retraction Groups.

\begin{tabular}{clcccccc}
\hline \multirow{2}{*}{ Type of bracket } & \multirow{2}{*}{ Arch wire } & \multicolumn{3}{c}{ Elastic chain } & \multicolumn{3}{c}{ Closed coil spring } \\
& Mean & SD & Duncan & Mean & SD & Duncan \\
\hline \multirow{5}{*}{ Standard stainless steel } & 0.018 inch & 8.4 & 0.70 & $\mathrm{C}$ & 10.0 & 0.0 & $\mathrm{D}$ \\
& $0.018 \times 0.022$ inch & 4.8 & 0.63 & $\mathrm{~A}$ & 6.4 & 0.70 & $\mathrm{~B}$ \\
& $0.019 \times 0.025$ inch & 4.7 & 0.48 & $\mathrm{~A}$ & 4.4 & 0.52 & $\mathrm{~A}$ \\
& F-value & & & & 168.68 & & \\
& 0.018 inch & 8.3 & 0.67 & $\mathrm{D}$ & 10.0 & 0.0 & $\mathrm{E}$ \\
Roth stainless steel & $0.018 \times 0.022$ inch & 4.9 & 0.88 & $\mathrm{~A}$ & 6.6 & 0.52 & $\mathrm{C}$ \\
& $0.019 \times 0.025$ inch & 4.6 & 0.52 & $\mathrm{~A}$ & 5.6 & 0.52 & $\mathrm{~B}$ \\
& F-value & & & & 132.41 & & \\
Hook Roth stainless steel & 0.018 inch & 7.3 & 0.67 & $\mathrm{D}$ & 8.0 & 0.0 & $\mathrm{E}$ \\
& $0.018 \times 0.022$ inch & 3.8 & 0.92 & $\mathrm{~A}$ & 6.0 & 0.00 & $\mathrm{C}$ \\
& $0.019 \times 0.025$ inch & 3.3 & 0.82 & $\mathrm{~A}$ & 5.0 & 0.00 & $\mathrm{~B}$ \\
& F-value & & & & 107.35 & & \\
Standard ceramic & 0.018 inch & 7.8 & 0.79 & $\mathrm{C}$ & 10.0 & 0.0 & $\mathrm{D}$ \\
& $0.018 \times 0.022$ inch & 3.4 & 0.70 & $\mathrm{~A}$ & 5.8 & 0.79 & $\mathrm{~B}$ \\
& $0.019 \times 0.025$ inch & 3.5 & 0.53 & $\mathrm{~A}$ & 3.9 & 0.74 & $\mathrm{~A}$ \\
& F-value & & & & 170.33 & & \\
Roth ceramic & 0.018 inch & 7.6 & 0.52 & $\mathrm{C}$ & 10.0 & 0.0 & $\mathrm{D}$ \\
& $0.018 \times 0.022$ inch & 4.7 & 0.48 & $\mathrm{~B}$ & 4.7 & 0.67 & $\mathrm{~B}$ \\
& $0.019 \times 0.025$ inch & 3.5 & 0.53 & $\mathrm{~A}$ & 4.6 & 0.52 & $\mathrm{~B}$ \\
& F-value & & & & 240.12 & & \\
\hline
\end{tabular}

Means with different letters vertically and horizontally in each bracket type have significant difference at $p \leq 0.05$.number for each group $=10$.measurment in degree. 


\section{DISCUSSION}

The present study showed that sliding canine on large rectangular wire by elastic chain with the aid of hook on Roth stainless steel bracket and with ceramic bracket gave rise to the lowest mean of degree of canine tipping. This result due to many reasons:

1. Arch Wire Size and Shape:

Using large rectangular wire gave rise to the lowest mean degree of tipping while

Round small wire produces the highest one. This is in agreement with other studies. $^{(18-20)}$

Rectangular arch wire usually produces little degree of tipping in comparison with round one, this is in agreement with the findings of Ziegler and Ingervall. ${ }^{(14)}$ Also the flexural rigidity affects the restoring couple on canine during sliding mechanics as mentioned by Moore and Waters. ${ }^{(21)}$ furthermore when light wire was used in sliding mechanics, wire deformation increased and the canine experienced greater tipping. ${ }^{(19)}$

Although rectangular arch wire offers good control for canine position during sliding, some degree of tipping movement is in veritably occur. This is in agreement with Irland and McDonald. ${ }^{(22)}$ and Kojima et al. ${ }^{(19)}$, The reason for this is the looseness of the fit of the arch wire in the bracket slot, where the tooth being moved along the arch wire.

\section{Bracket Material:}

The findings in this study showed that the mean degree of tipping in ceramic bracket is low and this may be attributed to the high friction of ceramic bracket and this is in agreement with Nishio et al. ${ }^{(23)}$ and also in accordance with Kojima et $a l .{ }^{(19)}$ who stated that as the friction force decreased, the tipping increase. Because the friction can reduce the force and minimize tipping movement. ${ }^{(24)}$

The other contributor is that ceramic brackets must be bulkier than stainless steel brackets and the ceramic design is much closer to a wide single bracket than is usual in steel because of low fracture toughness of ceramic brackets. ${ }^{(8)}$ and larger bracket offers more contact area between bracket and wire and could cause small wire inclination in the slot walls during their displacement. ${ }^{(23)}$ and this agreed with the result of the present study.

\section{Methods of Retraction:}

The present study showed that when using elastic chain the mean degree of tipping is lowest than using coil spring and this agreed with the finding of Webb et $a l .{ }^{(25)}$ who stated that close coil spring produces forces of greater magnitude than is necessary for orthodontic tooth movement. The tipping of the canine is increased when the orthodontic force increased. ${ }^{(18)}$ Samules et al. ${ }^{(26)}$ suggested that excessively rapid space closure might produce loss of tip and rotational control adjacent to the extraction site.

4. Methods of Attachment:

This study showed that attachment of the elastic chain on bracket's hook to retract the canine on large rectangular arch wire showed the lowest mean degree of tipping. This finding is in agreement with Darendeliler et $a l .{ }^{(27)}$ and Proffit et al. ${ }^{(8)}$ Who found that attachment extending toward the center of resistance as hook integrated into the bracket it can be used to shorten the moment arm and thereby decrease the amount of tipping when elastic or spring is used to slide teeth mesiodistally along an arch wire.

Also Daskaloginnakis ${ }^{(28)}$ stated that the application of force closer to the center of resistance of tooth during retraction, which, in turn, reduces the tendency to tip distally, this is because the force is applied at point more apical to the bracket position so that the bracket slot does not hit the wire surface. ${ }^{(29)}$ On the other hand, the attachment on the bracket tie wing increase the degree of tipping of canine because the distal force is applied coronal to the center of resistance so the center of resistance will move distally and the crown of the tooth will tip distally. ${ }^{(30)}$

\section{CONCLUSIONS}

There was no significance difference in the degree of tipping between standard and Roth design for both stainless steel and ceramic bracket in elastic chain retraction group for the three types of arch wire except the degree of tipping on ceramic bracket along $0.018 \times 0.022$ inch. 2 . When using stainless steel bracket, the degrees of tipping increase. The opposite is true with ceramic bracket.3. Attachment the method 
of retraction on the hook of bracket result in decreases in the degree of tipping. The opposite is true when the attachment occurs around the brackets tie wing.4. Canine sliding over arch wire of round cross section significantly produces high degree of tipping .The opposite is true with large size rectangular arch wire. 5. Sliding the canine using nickel - titanium close coil spring produce high degree of tipping than sliding it by elastic chain.

\section{REFERENCES}

1. Babu SH. Comparative evaluation of sectional canine retraction using modified opus loop and PG spring. A clinical study. M.Sc. Thesis, Saveelha Dental College and Hospital, Channel.2005

2. Rhee JN, Chun YS, Row J .A comparison between friction and frictionless mechanics with a new typodont simulation system. Am J Ortho Dentofacial Orthop. 2001; 119: 292 -299

3. Hayashi K, Uechi J, Murate M, Mizoguchi I .Comparison of maxillary canine retraction with a sliding mechanics and a retraction spring. A three - dimensional analysis based on a mid - palatal orthodontic implant. 2004; 26: 585 - 589 .

4. Hayashi K, Uechi J, Pyolee S, Mizoguchi I. Three - dimensional analysis of orthodontic tooth movement based on XYZ and finite helical axis systems. Eur J Orthod.2007; 18: 1- 7.

5. Staggers JA, Germane N. Clinical consideration in the use of retraction mechanics. J Clin Orthod. 1991; 25(6): 364 - 369.

6. McLaughlin RP, Bennett JC, Trevisi HJ .Systemized orthodontic treatment mechanics. First edition, Mosby Company.2001 Pp. 14, 13, 258, 111,110, 252, 258, 254.

7. Kojima Y, Fukui H .Numerical simulation of canine retraction by sliding mechanics. Am J Ortho Dentofacial Orthop.2005; 127(5): 542- 551.

8. Proffit WR. Contemporary Orthodontics. Second edition. St. Louis, Mosby Company. 2000 P. 345.

9. Elsheikh MM, Godfreg K, Manosudprasit M, Viwattanatipa N. A forsus distalizer: A pilot typodont study. Am J Ortho Dentofacial Orthop; 2004; 7(2): 107 - 116.

10. Eliades T, Bourauel C. Intraoral aging of orthodontic materials: the picture we miss and its clinical relevance. Am $J$ Ortho Dentofacial Orthop.2005; 127(4): 403412.

11. Hain M, Dhopatkar A, Rock P. The effect of ligation method on friction in sliding mechanics. Am J Ortho Dentofacial Orthop.2003; 123: 416 - 422.

12. Viazis AD. Bioeffecient therapy. J Clin Orthod. 1995; 29: 552 - 568.

13. Baty DL, Storie DJ and Von Fraunhofer JA. Synthetic elastomeric chain: a literature review. Am J Ortho Dentofacial Orthop.1995; 105(6): 536 - 542.

14. Ziegler P and Ingervall B. A clinical study of maxillary canine retraction with a retraction spring and with sliding mechanics. Am J Ortho Dentofacial Orthop.1989; 95: 99 - 106.

15. Sonis AL .Comparison of NiTi coil springs vs elastics in canine retraction. $J$ Clin Orthod.1994; 28(5): 293 -295.

16. Huffman DJ and Way DC. A clinical evaluation of tooth movement along arch wires of two different sizes. Am J Ortho Dentofacial Orthop.1983; 83(6): 453- 459.

17. Kula K, Kula T, Glaros A, Barlow J .Evaluation of printed and monitor - displayed images taken with digital cameras and impoted into the dolphin imaging system. Sem Orthod. 2004; 10(3): 220 -225.

18. Kojima $Y$ and Fukui $H$. Numerical simulation of canine retraction by sliding mechanics. Am J Ortho Dentofacial Orthop.2005; 127(5): 542 -551.

19. Kojima Y, Fukui H, Miyajima K. The effects of friction and flexural rigidity of the arch wire on canine movement in sliding mechanics: a numerical simulation with a 3 -dimensional finite element method. Am $J$ Ortho Dentofacial Orthop.2006; 130(3): 275- 285.

20. 20. Khambay B, Millett D, Mchugh S.Evaluation of methods of arch wire ligation on frictional resistance. Eur J Orthod.2004; 26(3): 327 - 332.

21. Moore JC and Waters NE .Factors affecting tooth movement in sliding mechanics. Eur J Orthod.1993; 15(3): 235 -241 .

22. Ireland AJ, McDonald F. The Orthodontic Patient: Treatment and Biomechanics. First edition. Oxford University Press. 2003; P. $181-182$

23. Nishio C, Motta AFJ, Elias CN, Mucha JN. In vitro evaluation of frictional forces 
between arch wires and ceramic brackets. Am J Ortho Dentofacial Orthop.2004; 25(1): $56-64$.

24. Burstone CJ. Charles J. Burstone on part 2 biomechanics. J Clin Orthod.2007; XLI (3): 139 -147.

25. Webb RI, Caputo AA, Chaconas SJ. Orthodontic force production by closed coil springs. Am J Orthod.1978; 74(4): $405-409$.

26. Samuels RH, Rudge SJ, Mair LH .A comparison of the space closure using a nickel - titanium spring and an elastic module: a clinical study. Am J Ortho Dentofacial Orthop.1993; 106(5): 464- 467.
27. Darendeliter MA, Darendeliter $\mathrm{H}$ and Uner $\mathrm{O}$.The drum spring (DS) retractor: constant and continuous force for canine retraction. Eur J Orthod.1997; 19(2): 115 130.

28. Daskalogiannakis J. Glossary of Orthodontic Terms. Quintessence Publishing Co. inc. 2000 Pp. 190- 204.

29. Tanne K, Matsubara $S$, Shibaguchi $T$ and Sakuda M. Wire friction from ceramic brackets during simulated canine retraction. Angle Orthod.1991; 61(4): 285- 292.

30. Lindauer SD. The basics of Orthodontic Mechanics. Sem Orthod. 2001; 7(1): 2- 15. 